Check for updates

London, UK

Cite this as: BMJ 2021;372:n523 http://dx.doi.org/10.1136/bm..n523 Published: 22 February 2021

\section{Covid-19: First doses of vaccines in Scotland led to a substantial fall in hospital admissions}

\author{
Ingrid Torjesen
}

Rollout of the Pfizer BioNTech and Oxford AstraZeneca vaccines has led to a substantial fall in severe covid-19 cases requiring hospital admission in Scotland, suggest the results of the first study to report on the impact of the UK's vaccination strategy. ${ }^{1}$

The results, available as a preprint, showed that four weeks after the first doses of the Pfizer BioNTech and Oxford AstraZeneca vaccines were administered the risk of hospitalisation from covid-19 fell by up to $85 \%$ (95\% confidence interval 76 to 91 ) and 94\% (95\% CI 73 to 99$)$, respectively.

The researchers from universities across Scotland and Public Health Scotland told a Science Media Centre press briefing on 22 February that their results were "very encouraging and have given us great reasons to be optimistic for the future." But emphasised that the study should not be used to compare the two vaccines as the study had not been set up to look at differences between them, was not randomised, follow-up was longer for people who received the Pfizer BioNTech vaccine because it was approved first, and the two vaccines were given to different patient populations. Specifically, the Oxford AstraZeneca vaccine was more likely to be given to very elderly people.

Asked whether the results provided reassurance that the Oxford AstraZeneca vaccine was effective in older age groups, despite lack of clinical trial data, and supported the decisions by the Medicines and Healthcare Products Regulatory Agency and European Medicines Agency to approve it for all age groups, lead researcher Aziz Sheikh, director of the University of Edinburgh's Usher Institute, said the results in older age groups were "very encouraging." But, he added, "At the moment we've not had the statistical power to do a stratified analysis."

Asked whether countries such as Germany, which have limited use of the Oxford AstraZeneca to younger age groups, should review their policies in light of the study data, Jim McMenamin, national covid-19 incident director at Public Health Scotland, said, “All we can do is present the science. It's over to the international community to consider that as part of the information available to them."

He added that the study had only looked at hospital admissions and that there were other endpoints to consider, such as admissions to intensive care and serious illness and deaths outside of hospital, including in care homes.

Only four weeks of follow-up data were available for the Oxford AstraZeneca vaccine, but the longer period for the Pfizer BioNTech vaccine showed that that the impact on hospital admissions lessened slightly five and six weeks after vaccine administration, raising the question of whether this decline might be related to waning immunity.

"We haven't specifically looked at waning immunity," said Chris Robertson, professor of public health epidemiology at University of Strathclyde, and statistics lead for the health protection group at Public Health Scotland, pointing out that these were preliminary data. "It's an important point, but we can't, at the minute, say anything about that," he added. "With our further analyses, when we've got a longer follow up then we will be able to provide more information.”

The researchers used a dataset that covers the entire Scottish population of 5.4 million to compare outcomes for people in Scotland who had received their first dose of a covid-19 vaccine between 8 December and 15 February. During this period, 1.14 million vaccines were administered and $21 \%$ of the Scottish population received a first dose: 650000 people received the Pfizer BioNTech vaccine and 490 ooo the Oxford AstraZeneca vaccine.

The researchers analysed GP records on vaccination, hospital admissions, death registrations, and laboratory test results every week to compare the outcomes of those who had received their first jab with those who had not.

Vasileiou E, Simpson CR, Robertson C, et al. Effectiveness of first dose of covid-19 vaccines against hospital admissions in Scotland: national prospective cohort study of 5.4 million people. [Preprint.] 2021. www.ed.ac.uk/files/atoms/files/scotland_firstvaccinedata_preprint.pdf.

This article is made freely available for use in accordance with BMJ's website terms and conditions for the duration of the covid-19 pandemic or until otherwise determined by BMJ. You may use, download and print the article for any lawful, non-commercial purpose (including text and data mining) provided that all copyright notices and trade marks are retained. 